I will mention what takes place in cases of sudden stopping of the movements of the heart, in consequence of an irritation of some peripheric parts of the nervous system. Whether the heart's movements depend, as I have tried to show long ago, ${ }^{*}$ upon an excitation from some substance contained in the blood circulating through the tissue of this organ upon its muscular fibres, or whether they depend upon some peculiar rhythmical change in nutrition, as ingeniously suggested by Mr. James Paget,+ their stoppage in the cases I shall mention is produced by a reflex action.

The sudden death which sometimes occurs when very cold water is drunk in a warm day, or in cases of a blow on the abdomen, of a sudden perforation of the stomach or intestine, of a wound of some abdominal viscus (without a notable hæmorrhage), \&c., seems to be due to a reflex stopping of the heart's action. I have made a great many experiments, which show positively that a sudden excitation of the abdominal sympathetic nerve kills, or diminishes the movements of the heart, by a reflex action. : The excitation goes up to the spinal cord chiefly along the great splanchnic nerve, and ascends the spinal cord until the place of origin of the par vagum, and through this pair of nerves it comes to the heart. This is proved by the fact that a section of either the par vagum, or the spinal cord, or the splanchnic nerves, allows any kind of irritation to be made on the abdominal sympathetic without a stopping taking place in the heart. In some animals, the influence of the irritation of the sympathetic in the abdomen is much more marked than in others; it is so, probably, in man. I have seen a gentleman drop down pulseless, in the most complete syncope, from a pain in the abdomen. The same gentleman is easily attacked by syncope from any kind of pain. One day, while I was trying to bleed him with the assistance of my learned friend Professor Natalis Guillot, he had, as soon as pricked by the lancet, a complete stopping of the heart's movements, and we thought for two minutes that he would die. I took him by his feet, which I put on my shoulders, and then rising, I held him, the head hanging down, and he gradually recovered.

It is by the reflex influence due to the sudden irritation of the branches of the par vagum in the lungs that chloroform has killed in the very rure cases in which the heart's action has been stopped before the respiration. In dogs, in which we can cause death in this way rather easier than in other animals, I have found that this mode of death never exists after the section of the par vagum. On the other hand, I have ascertained in the same kind of animals that the state of the heart is just the same as when death has been produced by the irritation (by galvanism) of the medulla oblongata and par vagum, or by the extirpation of the so-called vital knot.\$ Besides, another proof that it is in this way that chloroform kills in the cases which I try to elucidate is, that in some dogs, on which the heart's action has been suddenly stopped by the inhalation of a very large quantity of chloroform, I have been able to restore life by merely exciting the heart to contract by mechanical ex. citation (pressure on the chest).

I must point out, $\grave{a}$ propos of the stopping of the heart's action by a reflex mechanism, that one of the means employed to restore life in asphyxiated children-which consists in the alternative dipping of the body in warm and cold water - is a most dangerous one. No doubt that it is a powerful means of producing reflex actions, as long as any reflex power remains in the cerebro-spinal axis, but in this very thing lies the danger. I have seen puppies asphyxiated, and having no more respiration, while the heart was still beating fifteen or twenty times in a minute, killed at once on being dipped into cold water, the heart stopping by a reflex action. I do not intend to say that such a means ought not to be employed; I wish only to point out the chance of a sudden arrest of the heart's action, so that practitioners may be on the watch respecting this accident.

An extensive burn may also produce a stopping of the heart's movements, but it frequently produces other effects, which are much more interesting, and prove the great power of the nervous system on nutrition. In a very interesting paper by $\mathrm{Mr}$. Long, of Liverpool, $\|$ it is stated that death is cansed in many cases by an inflammation of the various viscera. The three following conclusions have been arrived at by Mr. Long: lst,

* Experimental Researches applied to Physiology and Pathology, 1853, pp. 77 and 111.

+ Proceedings of the Royal Society, May 28, 1857.

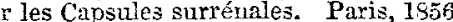

8 seen

de la Physial. de l'Homme, etc., No. 2, Avril, 1858, p. 217 FeD. $15+0$.

494
That in almost every burn, indeed in every burn, lesions of one or more of the viscera contained in the three great cavities exist, being according to their frequency as follows: abdomen, chest, head. 2nd, That the lesions of the different tissues contained in the abdomen are in the following order: mucous membranes, serous membranes, parenchymatous tissues; in the chest it is quite the reverse-namely, parenchymatous tissues, serous tissues, and lastly mucons; in the head-membranes, brain. 3rd, That the seat of internal inflammation corresponds sufficiently often with the external position of the burn, but that in a precisely equal number of instances no such correspondence can be traced. Mr. Curling, in a paper on the Influence of Burns on the Bowels, ${ }^{*}$ relates ten cases of ulcera. tion of the duodenum as a consequence of this powerful irrita. tion of the skin. Lastly, in a very remarkable paper, Mr. J. E. Erichsen ${ }^{*}$ gives the following as the result of observations of many cases of burns:

The cerebral organs were diseased in 33 out of 37 cases.

The abdominal viscer in 30 out of 40 in 31 out of 42 ",

I have given these numbers to show the frequency of this reflex influence of burns. When $I$ come to the deductions to be drawn from the facts I have mentioned in this lecture, for the treatment of disease, I will show the importance of the knowledge of this influence of burns, and I will show, also, what should be done against this frequently deathly influence, according to the view that it acts by a reflexion from the nervous centres upon themselves, or upon the thoracic or the abdominal viscera.t

(To be continued.)

\section{RIGIDITY OF THE OS UTERI}

AND ITS

\section{REMEDIES PRACTICALLY CONSIDERED:}

\section{BY JAMES GILMOUR, M.D., L.R.C.P. LOND.,} PHYSICLAN-ACCOUCHEUR TO THE LIVERPOOL IADIES' CHARITY.

WHEx the physician proposes the adoption of a new principle in the treatment of disease, or even attempts to recommend the substitution of one remedy for another, that other having been long known as possessing valuable powers in subduing and overcoming some serious morbid condition, he does so under a great responsibility. I consider it a duty I owe to. that profession of which I am an unworthy member, to express my opinion freely on the recognised remedies used in removing that troublesome and often tedious affection, known as rigidity of the os uteri, and to bring more prominently before the profession my own views, based upon lengthened experience, of the various modes of treatment, though such views may not be in accordance with those of other writers.

An unduly protracted labour, from whatever causes arising, is, at all times, a matter of deep interest to the observant practitioner, and of much disquietude to the patient herself. Such cases are by no means rare, and when they occur under the management of the young, and, to some extent, inexperienced accoucheur, frequently entail upon him a great amount of trouble and annoyance. The delay may sometimes be attributed to his want of skill, youth, or ignorance by the over-anxious friends of the patient; and whilst it should be his bounden duty to soothe any incipient alarm of his patient, he is also to use every legitimate remedy for the removal of the impediment. In some cases this can easily be done; but there are others where the most approved remedies will avail him but little, and will tax his judgment to the utmost extent. This rigid condition of the os uteri and adjacent structures is, therefore, a matter of deep interest to the medical attendant, for by his judicious treatment he will improve his patient, and reflect great credit upon his skill, hnmanity, and judgment.

It is not the object of this paper to enter upon the various canses of tedious labour, but $I$ would wish to say a few words upon a very common form of protraction, upon which I have devoted much time and thought for its amelioration and removal, and to detail a more efficacious mode of treatment,

* Mredico-Chirurgical Transactions, 2nd Series, vol. vii.

London Medieal Gazette, Jan. 1843, pp. 511 and 588.

\# That the nervous centres may act upon themselves, just as upon other organs, by a reftex action, will be shown hereafter. 
(and which, I firmly believe, may be adopted with more safety,) than that usually advised by others; and though the plan is neither new nor original, yet, I flatter myself, it may ke tried with a satisfactory result. The accoucheur, in these cases, must ever combine the suaviter in modo with the fortiter in re, and whilst he uses those remedies suggested to his mind by experience and skill, must bear in recollection the advice tendered by Blundell, "that it is necessary not only to be acquainted with the principles of midwifery, but to carry this knowledge to the bedside of his patient."

As a general rule, age has an important bearing on rigidity of the os uteri, thongh it may frequently depend on some local peculiarity. Women becoming pregnant about the age of thirty (though rigidity may occur at any age, or under any circumstances) invariably have tedious labours, and often tax the patience and ingenuity of the practitioner to their fullest extent before the labour is finally completed. At the age of thirty, the muscular fibres of the cervix and os uteri have, to a considerable extent, lost that peculiar elastic condition so requisite in a first labour, and which elasticity renders subsequent labours comparatively easy. The parts have lost, in some degree, the suppleness of youth, the mucous secretion is less plentifully supplied, and the areolar and muscular tissue are more condensed and nnyielding.

Although rigidity of the os uteri occurs, as a general rule, in women of a sanguineous and plethoric condition of system, yet it is occasionally found in those of an anæmic or cachectic state When it does occur in these latter, our management of such cases may incidentally become embarrassing; we require to hare all our knowledge at our fingers' ends; we may be puz zled, but we ought to be prepared to meet the difficulty, and carefully to watch and assist nature. Bandelocque has well observed, that "the accouchenr ought then, in none of these cases, to content himself with being a mere spectator. That patienee which is recommended by some as his principal virtue ought to have its limits; an excess of confidence in the secret resources of nature, which some people boast of with a sort of assurance, being not less condemnable than the inconsiderat mancurres of those ignorant men in whom rashness supplies the place of knowledge."

An extensive practice in midwifery, combined with careful study, compels me to assert that there is yet something more to be learned about cases of rigidity than what is stated by medical authorities, and that much of what is written on the subject will searcely bear the test of examination, but will also admit of much improvement. We find one author writing much about the good results of bleeding, and another warning us against it ; some recommend patience and opium ; others forbid renesection as positively injurious. The practitioner, if young, is here left, like a ship in a storm without an anchor he must seek a harbour of safety by his own mental resources.

In a practical paper I consider it quite unnecessary to enter into any elaborate definition of what is meant by rigidity of the os uteri and vagina, because such information may be obtained from any standard medical authority. This much, however, I think necessary to say, that rigidity may exist in the cervix and os uteri, or in the vagina and perinæum, or in all conjointly. We find that where one part is affected, the adjacent structures partake more or less of the same unhealthy condition. We may, with Dewees, define rigidity to be "an unusual resistance to the efforts which the fundus and body of the uterus make to expel their contents," or such a condition of the cervix, os uteri, and vagina, as resist for a longer time than natural the expulsive power of the uterine organ itself. Writers have divided rigidity of the os uteri into various stages: the old writers were simple and intelligible; the modern authors more complex and incomprehensible. It would waste time to enter upon these numerous divisions; some are true, and some are purely imaginary - as, for instance, the "relative rigidity" of Dewees, where " the circular fibres of the uterus act with a force superior to the longitudinal." I confess myself to be totally ixnorant of the means of knowing this during labour; the idea is purely Transatlantic; the notion is a myth-exists more in the imagination than in reality. Such a condition is purely presumptive and fallacious.

When the rigidity is confined to the cervix and os uteri, the ris a tergo (uterine force) is insufficient to produce dilatation the pains are inefficacions for the purpose desired; the cervix feels hard like leather; the os may be closed, or if partially open, may be like a ring, thick and resistent, or hot, dry, and undilatable--deficient of the usual mucus requisite in easy dilataticn. The pains are frequently very acute, and of a cutting character, and when the os does not yield favourably to the expulsire powers, and the rigidity persists unrelieved, consti- tuitional symptoms set in, such as a febrile condition of system, irritability of temper, anxiety about the result, and, last of all, exhaustion. The whole progressive train of symptoms of natural labour becomes deranged. If the rigid state still continues unmitigated, the parts will become hot and swollen from continued pressure and interrupted circulation; the tenderness may be so great, that the making an examination will produce intense suffering; an offensive discharge from the vagina, and, it may be, retention of urine, indicate still further mischief. These local and constitutional symptoms may occur before the os uteri has undergone full dilatation; they :ure the results of the ineffectual efforts of the uterus to force the head through the os, and the longer such a state of things continues, the worse will be the termination.

The first great remedy in rigidity (vaunted by authorities) is bleeding; and I do not for a moment deny but that in some exireme cases it may be effectual for its removal; nevertheless, I assert that too much stress is placed on this remedy, to the exclusion of others; and of the se last, I place tartar emetic in the front rank. Bleeding in cascs of rigidity was known to Hippocrates; it was also advocated subsequently by Mauriceau and others, and is so at the present time, especially by Ramsbotham. I acknowledge that in rigidity with a plethoric constitution, and much excitement of the heart and arteries, it may have its advantages, and in rare cases of this kind it may be indispensable; still I have a great objection to deprive the system of much blood at a time when we cannot anticipate the afteroccurrences, and know not how much the recovery of the patient may depend on a sufficient supply of this material; every drop of blood may be required for this important purpose. We may have post-partum hæmorrhage; for, unfortunately, bleeding in rigidity is not a prophylactic, and will not prevent this dangerous and alarming accident: venesection is a powerful agent, but may be productive of much subsequent evil. It is our bounden duty, in every case of labour requiring exhaustive treatment, so to use our remedies that we may husband the strength for succeeding attacks, of whatever nature they may be, and for the future recovery. The loss of a few ounces of blood might be the stumblingblock to a woman's safety, and, especially in cases of flooding, might put her life in imminent peril. There is, of necessity, more or less blood lost during and after delivery, and we know not beforehand what that quantity may be; therefore we should be very careful in advising its abstraction. Such abstraction, as a rule, leads to exhaustion, when performed in cases of rigidity and protracted labour; and from experience it is well kiown that a woman is often a long time in making good the blood taken away. Bloodletting is of course inapplicable to cases of disproportion between the head of the foetus and the maternal pelvis, and also when the protraction depends on deficient uterine action. It is found that bleeding exerts no beneficial effect on the condition of the os uteri, unless sufficient has been taken to produce either syncope, nausea, or exhaustion, the usual sequelæ of large venesections: hence a powerful argument for the substitution of nauseating medicines for the use of the lancet. Dewees remarks that rapid improvement took place always, in several of his cases of rigidity, as soon as sickness or fainting occurred after the bleeding; and Dr. Good makes the important admission that great benefit may be obtained in those cases which he designates as "implastic rigidity," where the parts are rigid, hot, rry, and tender, by bleeding to a few ounces, and then followed up by nauseating doses of hippo or tartar emetic; the uterus acting with greater freedom, and the os uteri becoming "lax, yielding, and compliable."

A greater caution may be given with regard to the second great remedy in rigidity-viz., opium. Here also much discrimination is required, because of the discrepancy of writers. For a long time $I$ have ceased to administer opium in cases of rigidity, and I look upon it as positively injurious. It may allay or retard pain, but even then it may do harm; it has no power of producing relaxation; it may suspend labour when given in large sedative doses, but in cases of rigidity I question the utility of such suspension; the cessation of uterine action is anything but desirable. The relief of pain bears no comparison to the safe conduct of the patient through a rigid, wearisome labour; and, as the late Dr. Ramsbotham justly observes, the effects of opium are not confined to the disturbance of the labour previous to the expulsion of the child, but they are continued and injuriously exerted upon the delivery of the placenta, and that even fluodings and other mischiefs arise from its use. It has often puzzlea me to ascertain how opium came to be tried at all in rigidity of the os uteri. Burns was greatly to blame in this matter, because, throughout all his chapters on natural and preternatural labour, we find opium 
recommended in a very unphysiological and empirical manner. His instructions are vague, and, to a person conversant with the true mechanism of parturition, meaningless. An important question here arises : are we justified in suspending labour by a large dose of opium, merely to gain time, in a case of rigidity? Nous rerrons. I think not, unless under some rare or peculiar circumstance. And, again, it may be asked, shall we leave such cases to nature? - shall we allow nature, irrespective of time, to complete the case unassisted? Decidedly not. This is the reasoning of the dullard, who is slow to embrace improvements in medicine, and who puts implicit faith in the vis medicatrix nature, forgetting that, in some cases, nature is unable to complete her own work, and that every moment of delay may endanger mother or child. Such doctrine is un. sound.

The third, last, but most important remedy used in cases of rigidity of the iterine passages, is the administration of nauseating doses of tartar emetic. Lowder recommended the trial of emetics many years since, founded on the observation, that spontaneous vomiting in labour is generally followed by relaxation of the os uteri; but the remedy gradually fell into disuse, and is not now advocated. Nauseating medicines have long been given in these affections with manifest advantage. We are indebted to Dr. Kennedy, of Dublin, for bringing before the profession the true advantages of tartar emetic, and since that time an occasional paper has appeared in support of his views; but I feel that sufficient has not been written to impress it on the mind of the young practitioner with force and effect. The natural sickness of labour always has a beneficial influence in inducing relaxation, unaccompanied by subsequen't evil, and for the same reason, artiticial nansea has a powerful influence in subduing rigidity of the os uteri or vagina, and is so safe in the administration, that it is a well-known fact that puerperal or peritoneal inflammations are rarely seen where tartar emetic, as a nauseant, has been judicionsly given; there seems an almost perfect immunity of system from these diseases afterwards. Churchill states that tartar emetic, in rigidity of the os uteri, is " an exceedingly valuable remedy, perfectly safe, and very successful." I have no desire, though I strongly praise the drug, to insinuate that tartar emetic possesses any specific effect on the gravid uterus, similar to that which the older writers attributed to borax or cinnamon, or the moderns to ergot of rye; yet $I$ have often noticed that during its administration uterine action is improved, and the labour accelerated; and there is another striking fact, that where it does not produce either nausea or vomiting, (and there are many such cases,) I have seen the uterus act with much greater vigour, and the pains become more effectual. This may not depend on any peculiar action of the remedy upon the uterus, but may probably be owing to the removal of the resisting force, allowing the uterus to act with greater freedom; nevertheless I place the idea before the profession, and it may assist future observers.

In thus adrocating the exhibition of tartar emetic in cases of rigidity, as superior to any other mode of treatment, $\mathrm{I}$ am aware that the doctrine is neither new nor original; but it has not hitherto been discussed in its true physiological and practical bearings. Having used it for more than twelve years with uniform success, I am in a position for soliciting for it a more extended trial, and the more especially so as there is much discrepancy found in authors on the subject. We have the authority of Rigby, that nauseating remedies "do no good, but harm," contra Churchill and Collins, who speak highly in their favour. I say here to my young brethren in medicine, that they must not trust implicitly to what they read in books; many of them are truly valuable and trustworthy, but others (and of these there is a large number) are written to suit a purpose, and contain trash. I speak plainly when I tell them to pin their faith to no author's dictum. They must learn to think for themselves; they must strike out manfully, but thoughtfully, in their desire for practical knowledge. If they do this, they will soon discover that many book dogmas are dross, mere stubble-rotten pillars to lean upon in their hour of difficulty.

"To think rightly, is of knowledge; to read with profit, is of care."-Topprzr.

But I digress. Ramsbotham, in writing against the use of tartar emetic in cases of rigidity of the os nteri, states that vomiting is not the cause of relaxation of the os uteri, but the effect. This may be true, but we frequently have dilatation of the os uteri without vomiting; the latter is not essentially necessary to the former. I cannot see how his assertion is opposed to the exhibition of nauseating remedies. Artificial nausea relaxes the whole muscular system, as well as the cervix and os uteri; it enables the fundus and body of the aterus to overcome the disposition to resistance found in the cervix. I do not assert that vomiting, per se, would be judicions in all cases of rigidity, though I have never seen it do harm where it has occurred.

Before giving tartar emetic, I always ascertain that there do not exist certain unbealthy conditions of system, as organic disease of the heart or lungs, \&c., which would make me hesitate to prescribe the remedy in preference to some other mode of treatment. Under such circumstances continued nausea might be productive of serions mischief, if not actually of risk to life. Bleeding would be even more hurtful, and our best policy would be a temporizing one, to act according to circumstances. Time would be of vast consequence, and we should exercise the most vigilant and diligent attention. As it is not the purport of this paper, however, to enlarge upon this most important complication, I pass it by with the remark, that a high degree of rigidity is seldom connected with any serious organic or debilitating disease.

Although I strenuously advocate the use of tartar emetic in rigidity, yet I am not blind to its injudicious or indiscriminate employment. Galen tells us, "sive purgans dederis sive vomitarium, prima exhibitio in tua potestate est, reliqua sibi fortuna vindicat." However, independent of this caution, I do not know of any drug more easily managed, or the benefit of which to the constitution can be nore carefully regulated, or in the exhibition of which less injury is done to the system. At all times great prudence, and much patience as to the result, are requisite; and unless we bear these things in mind, we may be disappointed in its action and benefits in a case of protracted rigidity. In waiting at the bedside for the good result of any medicine, especially upon the uterus, we must not forget the caution given by the late $\mathrm{Dr}$. Gooch, that in tedious labour there is one most important medicine always to be carried abont with us, and that is "tincture of time" Calm endurance, without undue haste, is essentially necessary in watching the progress of a lingering labour, and more especially if we are exhibiting medicines to hasten the result.

As regards any particular plan for giving tartar emetic in cases of rigidity, I have only a few words to say. If the rigidity be great, and the patient plethoric, I usually give an emetic dose to begin with, and afterwards continue the nauseo by diminished doses. Symptoms of improvement soon show themselves; the hard and firm cervix and os uteri become thinned and softened; there is increased mucous secretion; the os feels moist, relaxed, and dilatable; and here it may be noticed that, as soon as symptoms of relaxation appear, the labour pains will become stronger, and the patient will bear them with greater fortitude. Though there is increased pain, there is greater hope; the woman feels that the impediment is being removed, and she suffers in confidence.

Tartar emetic has this great advantage over bleeding, that we accomplish the desired purpose of producing relaxation, and do not deprive the system of blood at a time when it may be imperatively required. If we bleed to exhaustion, there may still be hæmorrhage, and most troublesome will then be our management. A gain, I have known some of the worst forms of puerperal inflammations to follow after bleeding, but never after the tartar emetic; and we have the great authority of $\mathrm{Dr}$. Lee, who, whilst cautiously recommending bleeding, concludes with this significant remark - "Bleeding is absolutely injurious by inducing debility in the puerperal state." This, I acknowledge, is in direct variance with the experience of Dewees, whose heroic bleedings in America have found few followers in this country, and the practice is now discarded as erroneous, if not dangerous.

It may be thought by some that I write too strongly on the subject, and that I am too sanguine as to the good results. My answer to this is, that the reasons and arguments here adduced are fruits of many years' patient observance of the utility of the method of treatment pursued. In my early days I prac. tised bleeding to a considerable extent, and, although I acknow. ledge its great power in overcoming the resistance of rigidity, yet I found it highly injurious to my patients' recovery afterwards. I seldom resort to it now. Tartar emetic answers every purpose, and I invariably exhibit it (when necessary) in all cases of rigidity of either os uteri, vagina, or perinæum. I have no fear of subsequent inflammatory diseases; I seldom see such a thing as hæmorrbage, and I have an inward satisfaction that my patient will pass through the puerperal state in com. parative comfort and safety. Blundell talks much about arte non vi; but the grand secret is to be able to discriminate with judgment when to interfere and when to abstain.

I believe that tartar emetic has another important advantage over bleeding; and that is, that the parts are better prepared 
for delivery by instruments, should it be deemed expedient to resort to their use. Tartar emetic has a more peculiar action on the vaginal mucous membrane than bleeding appears to have, giving an increased mucous secretion with greater dilatability. The general relaxation of the whole system from artificial nausea appears to banish many of the symptoms inimical to the use of instruments; irritability of mind especially gives way, and we seldom find our patient pass into that stage of exhaustion so much to be dreaded under the circumstances; the medicine has rather a soothing effect in its constitutional action, producing a sedative as well as a relaxant systemic operation. Though the use of instruments is seldom necessary in cases of simple rigidity, yet, from failure of efficient pains, or from the remedies used being inefficacious, such a necessity will occasionally arise, and it is but right that we should have a clear perception of how to behave under such circumstances. If the rigidity be confined to the perinæum, the lever will be found the better instrument. The propriety of instrumental delivery in rigidity of the os uteri and vagina would form a most interesting subject for examination; but I must, ex necessitate, decline the investigation.

This paper would be incomplete without having a few words with those who object to medicinal interference in natural labour, though such labour may be lingering from rigidity or various other causes, or may be simply one of protraction beyond a certain definite period. It is often stated that as pain is essentially a part of the parturient process, we ought not to interrupt the efforts of Nature, however painful or slow, because Nature is all-sufficient for the accomplishment of her own work. There is a plausibility in this sort of argument, but it is superficial, and fails on deeper examination. Such persons reason something like Hippocrates, when he states "quia aliqua parte corporis dolentes, ut plurimum dolorem non sen. tiunt, illis mens laborat." It is our bounden duty to alleviate pain at all times, when it can be done without hazard; pain, that "ill that flesh is heir to," is an indispensable evil, and it ought to be our study to mitigate or remove it. I fear we can scarcely apply the beautiful saying of Romberg, that " pain is the prayer uttered by the nerve for healthy blood," to the pain of labour; it may, with propriety, be rather called the warning bell informing us of disagreeable news, or danger not far distant. I agree with Ramsbotham, that pain in labour is occasioned by the sensitiveness of the nterus, and by the pressure of some part of the contents against the cervix and os during contraction. Labour-pains are merely the external evidences of the presence and progress of those powers by which the process is tinally to be consummated. As a rule, women in labour of primiparre suffer more actutely than others, verifying the remark of old Ambrose Pare, "but beckus that the travail of the tirst time of ehilde-birth is wont to be verie difficult and grievous;" yet it sometimes happens that some women suffer almost no pain during the progress of labour, and are often agreeably surprised when told that all is over. Pain was let loose from the box of Pandora as a punishment for us poor mortals; it is suficiently unpleasant for the sufferer to seek relief from it, and such relief is legitimately desired from the physician. In rigidity of the os vieri, where the natural pain is intensified, it is demanded of us to afford some relief from it, if not its entire removal. If pain be the "sentinel of health" (Sieveking), we must not neglect the admonition given us. Chloroforn met with great and undeserved opposition when first introduced, but its enemies are now silent, because vanquished.

If these few imperfect remarks, written in haste, should lead others to investigate this subject for themselves, the writer will have gained all that he desires from their publication. The arguments have been the result of patient inquiry and careful, though extensive, practice. None of us should be content to tread the hacknied path of others without being satisfied of the safety of the road, and we are all morally bound to give the result of our experience, provided these results have been honestly studied. The aucient Greeks and Romans would not trouble themselves to investigate the beautiful truths of Christianity, but accuiesced silently in the general persuasion that all they had to do was to practise the duties of morality, and worship the Deity more patrio. It should not be so in medicine; new facts and discoveries are coming to light every day, and each of us, however humble be our position, may add something valuable to the general storehouse of knowledge. Dr. Beddoes, in his preliminary dissertation to the works of the great Brunonian theorist, makes the trite remark, that " the greatest repute in medicine affords scarce the slightest presumption of superior skilfulness." My opinion is, that tartar emetic requires a more comprehensive trial in cases of rigidity; I feel satisfied that it should almost supersede bleeding in this morbid condition. It must never be forgotten, that where there is deficient uterine action from any cause, this remedy will be found comparatively useless-nay, may even be injurious.

As regards the minor remedies in this affection, the warm bath is seldom available in private practice, and is of little benefit; lubricating the os and vagina with nnctuous substances does really no harm. I have had no experience of the application of belladonna to the os, as recommended by Gardien, but I should fear it injuring the foetus in its passage through the pelvis.

In the management of these cases, great patience, forbearance, and judgment are required from the practitioner, but he is "steadily to do his duty, being neither swayed by fears nor entreaties, nor by a selfish regard to the saving of his own time." (Burns.)

Liverpool, 1858 .

CONGENITAL HEMIPLEGIA IN A STILLBORN CHILD, IN A CASE OF PLACENTAL AND FUNIS PRESENTATION.

BY GEORGE D. GIBB, M.D., L.R.C.S.I., PHYSICIAN-ACCOUCEEUR TO THR ST. PANCRAS ROYAL DISPENSART, AND TATI PHYSICTAY TO THE WEST LONDON DISPENSARY.

Is the following case, I think there are features of sufficient interest to render it worthy of being placed on record. Early on Sunday morning, the 3lst October, I was hurriedly sent for to see Mrs. C- in labour with her fifth child. At two o'clock A.M. I reached her house, and made an immediate examination: the os uteri was very high up, but fully dilated, with an entire placental presentation; and a considerable loop of the cord was down, which protruded externally through the vulvæ. She had been in labour, it was stated, off and on, for two days, the pains being strong only the night previous; and she had lost a great deal of blood; in fact, during the last three months of utero-gestation, she had been subject to repeated attacks of hæmorrhage. A midwife of some experience was present, and I learned from her that the cord had been down upwards of an hour and a half, and that she could feel the child, through the placenta, to be in a transverse position. Pulsation had ceased in the cord shortly after it came down; and as there was a good deal of hæmorrhage still going on, I considered it advisable to act with energy, and made up my mind to effect delivery by turning the child. The pains had by this time become quite insignificant and of little power the membranes had been ruptured for some hours, and the pulse was quick and getting weak. I introduced my hand into the vagina, and endeavoured to perforate the placenta, in effecting which I discovered the head presenting above it; as much of the placenta as could be got away was therefore detached. Whilst doing this, strong, energetic pains commenced, forcing the child's head downwards. My hand was withdrawn and on waiting a little while I saw that the bleeding had wholly ceased, and labour promised to go on well. In three hours and a half a still-born male infant was expelled; the remains of the placenta followed immediately after, and the nterus was firmly contracted. Thus was an agreeable termination given to a dangerous case.

The child was well made, but the fingers of its left hand were rigidly contracted, as were the elbow and the toes and knee of the same side; they had evidently been so for perhaps many weeks. The opposite side of the body was unaffected. The contracted fingers could not be forcibly straightened without rupturing the tendons. Suspecting this to be hemiplegia, I examined the brain, and found the remains of an old clot in the substance of the right hemisphere, above the lateral ventricle; the left parietal bone was extensively ecchymosed, and the pericranium could be peeled off with the finger. In other respects, with the exception of general congestion of all the vessels, from the manner of its death, nothing abnormal was found. This condition of the infant is explained by the occurrence of an accidental blow received three months ago by the mother on the right side of the abdomen, from the slipping of the end of a board which was being planed, most probably expending its force on the child's head in utero; for it may be also mentioned, that the scalp was bruised over the 